\title{
Diagnostic ultrasound in the athlete's locomotor system
}

\author{
H. Mellerowicz MD, E. Stelling MD and A. Kefenbaum MD \\ Orthopaedic Clinic and Outpatient Department, Free University, Berlin \\ Oskar-Helene-Heim and Institute for Sports Medicine
}

Keywords: Sonography, diagnostics, locomotor system, damage, injury

\section{Introduction}

In international high performance sports, the considerable rise in performance in recent years has led to the limits of stress resistance being more closely approached. Through the greater number of competitions and diminished periods of recovery, further potential for sports injuries has developed. Even in leisure and health sports, lesions of the locomotor system are more frequent due to the greater number of highly motivated but often untrained participants ${ }^{1}$.

The majority of these injuries are soft tissue lesions. For a proper diagnosis in this field, manual clinical methods such as palpation, percussion and functional locomotor examinations are available. These are complemented by the following; radiology, xeroradiology, computed tomography and, recently, nuclear magnetic resonance (NMR). Clinical methods depend very much on the doctor's subjective experience.

Ultrasonography closes the gap between these methods and can represent differentiated soft tissue structures economically in time and $\operatorname{cost}^{2-7}$. A special advantage for sports medicine is that a dynamic picture of soft tissue can be achieved. There is no radiation and therefore no side-effects are caused by this method. Graphic representation of injuries leads to a better comprehension on the athlete's part, thereby improving his motivation for both rest and medically controlled training during recovery. The limits of ultrasonography are that the findings are frequently considered non-specific, as only statements regarding the echo-pattern of tissues and their limiting zones can be made. Resolution of structures of less than $2 \mathrm{~mm}$ is limited. Statements concerning the joints are also limited as the bony structures interfere and underlying structures remain obscured in the sound shadow cast by the bone.

The examination requires a modern short-focus, high-frequency, real-time linear array transducer. Acoustic signals are sent out and received by the transducer. The echoamplitudes of the different kinds of tissue appear as a pattern on the screen. Due to its properties, sound may be absorbed, let through

(C) 1990 Butterworth \& Co (Publishers) Ltd 0306-3674/90/010031-09 or reflected at the borders of the tissue transmitted through: fluid, hyaline cartilage; partial reflection: fibrous connective tissue, cartilage, periosteum, perichondrium; total reflection and absorption: bones ${ }^{7}$.

In 1984 we introduced sonography in our orthopaedic and sports medicine department and gained experience on over 5000 patients. We see the following indications as being the focal points of interest for the application of ultrasonography:

Muscle Differentiation between strain and muscle tear (quantitative differentiation), haematoma, contusion, rupture and myositis ossificans

Arthrosonography of the shoulder, knee, ankle, hip and wrist joints (inclusive of bursae and ganglia)

\section{Achilles tendon and peritendinous areas}

Follow-up of apophysial ruptures, fractures and pseudoarthrosis.

\section{Muscle}

Muscle injuries are frequent in sport. Diagnosis was first made on clinical criteria ${ }^{8,9}$ and was confirmed through xeroradiography, computed tomography, arteriography, histology and, if necessary, evidence of CPK, GOT and GPT in the serum. Due to the invasiveness and expense of these methods, they could only be applied in selected cases. Here ultrasonography provides the possibility of recording injuries and degenerative processes in a noninvasive, reproducible and dynamic way.

In the image the muscles are represented as a relatively echo-poor structure, interlaced with linear regular echogenic structures, the so-called fibroadipose septa6,10,11. They are united by smooth echogenic zones, corresponding to the muscle fascia. This representation is similar in all regions of the body ${ }^{10}$. Muscular activity, in the sense of contraction, can be dynamically observed. Its sonographic equivalent is represented by a broadening of the muscle fibres and widening of the septa.

Muscle fibre tears are shown on the sonograph as being echo-poor zones, interrupting the normal structure (Figure 1). In a more serious degree of injury with haematoma formation, sharply defined echofree zones with sound amplification on the far side will appear (Figure 2a). However, older injuries with haematoma coagulation as well as seroma present an 


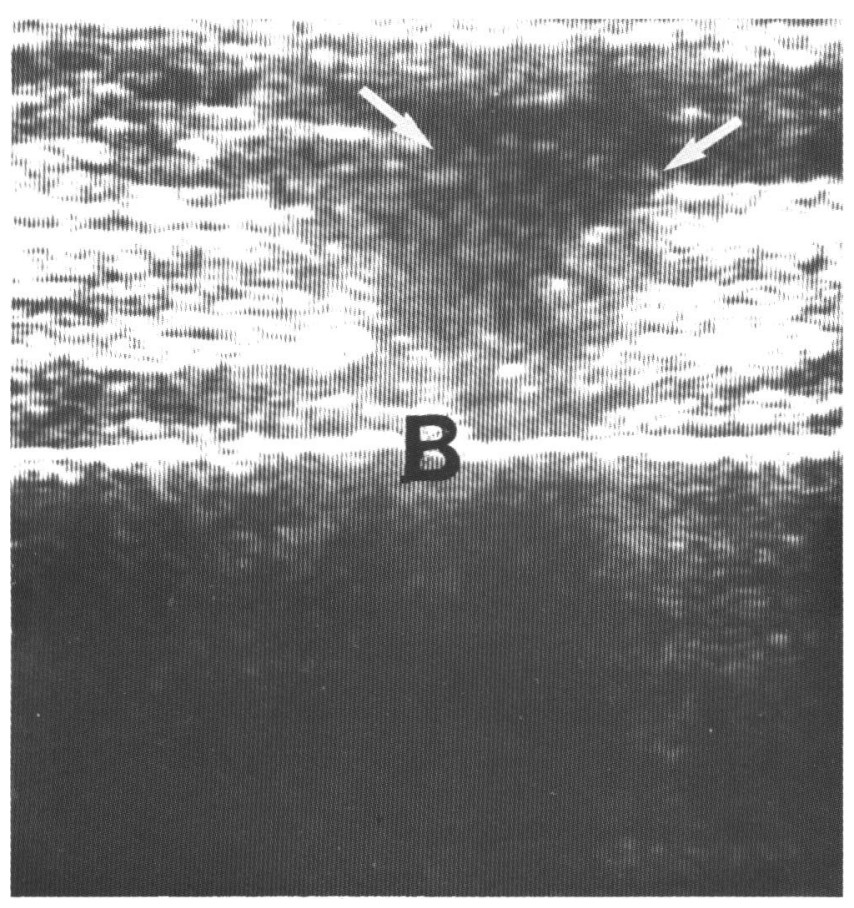

Figure 1. Complete muscle tear $\rightarrow$. Break-up of fibrousadipose septa after experimental detachment on cadave specimen. Sound reflection on the bone underbeath B. Longitudinal section - quadriceps femoris

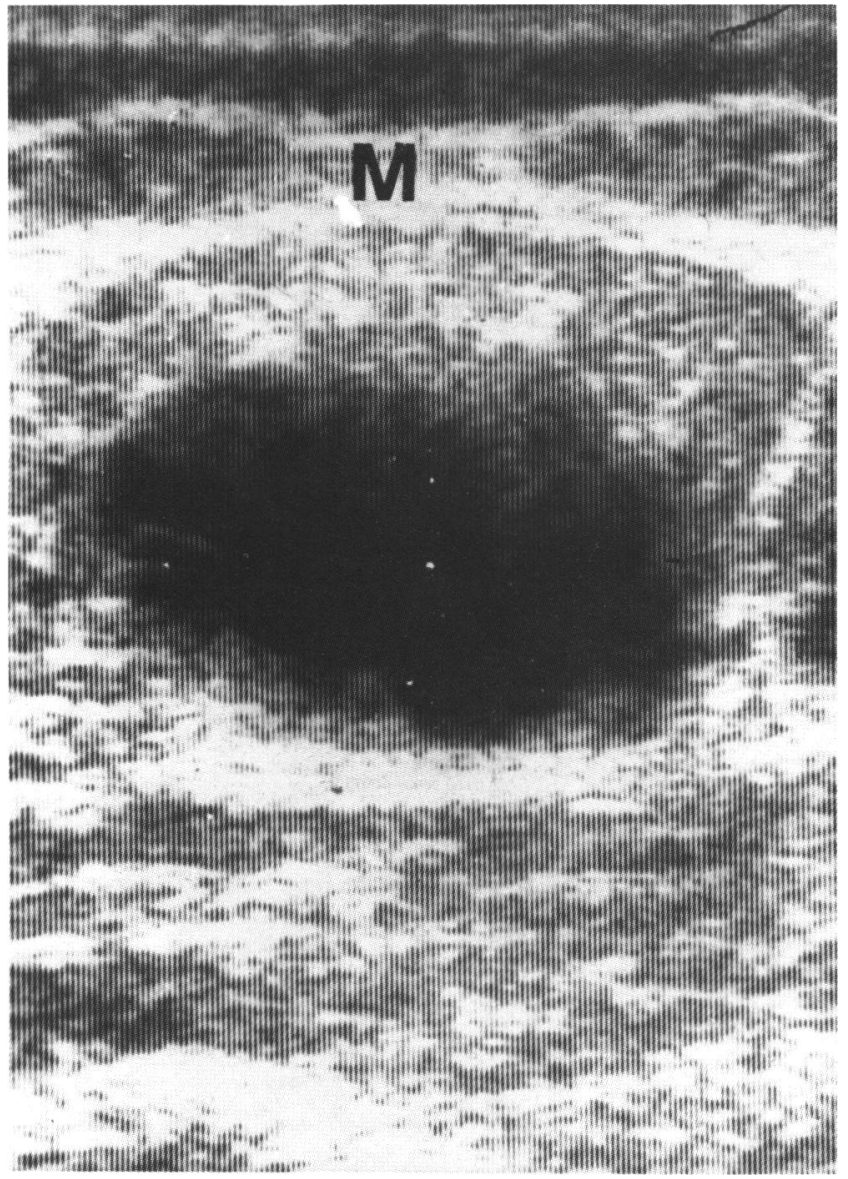

Figure 2a. Muscle fibre laceration with bleeding. Large demarcated echo-poor zone, $2 / 3$ of the cross section. Sound amplification on the rear area ( $M=$ muscle fascia). Longitudinal section - biceps femoris 10 days after a sprint trauma almost identical picture. In the course of undisturbed healing, echo-poor structures are subsequently replaced by echoes indicating healing by resolution and transformation (fibrosis, scar formation) (Figure $2 b$ ). These changes signify an increasing resistance to stress. Echogenic thickened areas representing 'muscle scars' may still be seen years later. Persisting pain due to non-reabsorbed haematoma or early myositis ossificans can be defined (Figure 3). Here, the area of calcification becomes apparent, sharply defined through a dense sound echo with distal acoustic shadowing ${ }^{12}$. Clinical classification based on ultrasound findings is important for the continued treatment of muscle injuries $3,5,6,8,10,11$.

For the purpose of verifying these observations, cadaver examinations were carried out with welldefined induced lesions such as myotomy and haematoma. On the basis of these experiments, we found a differentiation of injuries smaller than $2 \mathrm{~mm}$, as well as identification of haematoma less than $5 \mathrm{ml}$, was not possible.

\section{Arthrosonography}

Arthrosonography offers a dynamic examination of the joint's soft tissues, as long as they are not overshadowed by osseous structures.

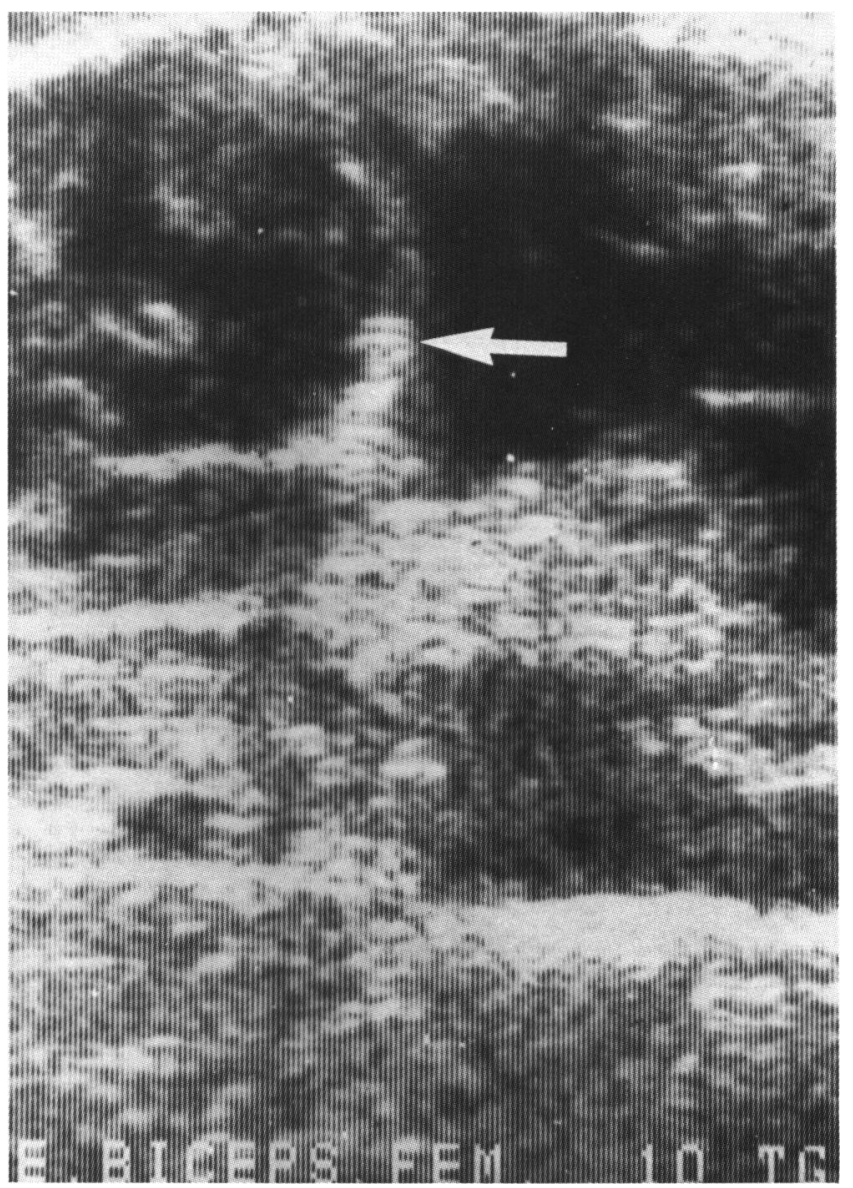

Figure 2b. Control sonography after 10 weeks. Only isolated zones of slight thickness with increasing restructuring through echo-rich septa (fibrosis) $\rightarrow$. Longitudinal section 
Table 1. Diagnostic criteria

\begin{tabular}{|c|c|}
\hline Clinical & Ultrasound \\
\hline Muscle strain & $\begin{array}{l}\text { No sonographic proof, as the injury } \\
\text { lies below resolution }\end{array}$ \\
\hline Rupture of the muscle & $\begin{array}{l}\text { A breaking-up of the structure of } \\
\text { the fibro-adipose septa; the } \\
\text { quantitive size of the rupture is } \\
\text { determinable }\end{array}$ \\
\hline Contusion of the muscle & $\begin{array}{l}\text { Displacement of muscle fibres with } \\
\text { echo-poor zone corresponding to } \\
\text { bleeding }\end{array}$ \\
\hline Myositis ossificans & $\begin{array}{l}\text { Sharply defined very echogenic } \\
\text { reflex with distal acoustic } \\
\text { shadowing. Sonographic precedes } \\
\text { radiological evidence }\end{array}$ \\
\hline
\end{tabular}

\section{Shoulder}

Ultrasound examination of the shoulder enables identification of rotator cuff injuries, as well as degenerative and traumatic changes to the soft tissues $^{13-15}$.

The examination takes place on the seated patient allowing free arm movement for dynamic investigation (Figure 4). Scanning in standardised sections of the shoulder is required. The first examination takes place in the so-called coracoacromial window. Here, the mains tructures of the rotator cuff (m. subscapularis and $\mathrm{m}$. supraspinatus muscles) as well as the long biceps tendon and subacromial-subdeltoid bursa are both imaged and differentiated ${ }^{13,14}$. In the dynamic examination of abduction, the transducer is directed to show the engagement of the humeral head under the acromion (impingement view).

Complete rotator cuff ruptures show as echo-poor zones breaking through the whole structure and the rotator cuff boundary layer (Figure 5). In dynamic examination lesion size can be estimated by means of representation in several levels. Anatomical classification of individual muscle groups as well as the position of the lesion is possible. Increased echogenic

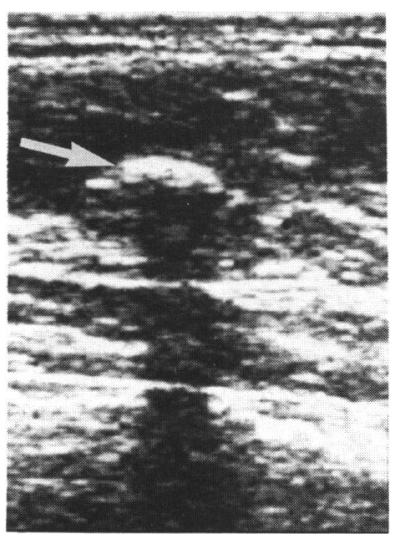

Figure 3. The start of myositis ossificans after contusion trauma. Eight weeks post-trauma. Longish sound-proof zone $\rightarrow$ with partial extinguishing of bone reflexes lying underneath. Fibrosis with beginnings of calcification. Longitudinal section - biceps humeri

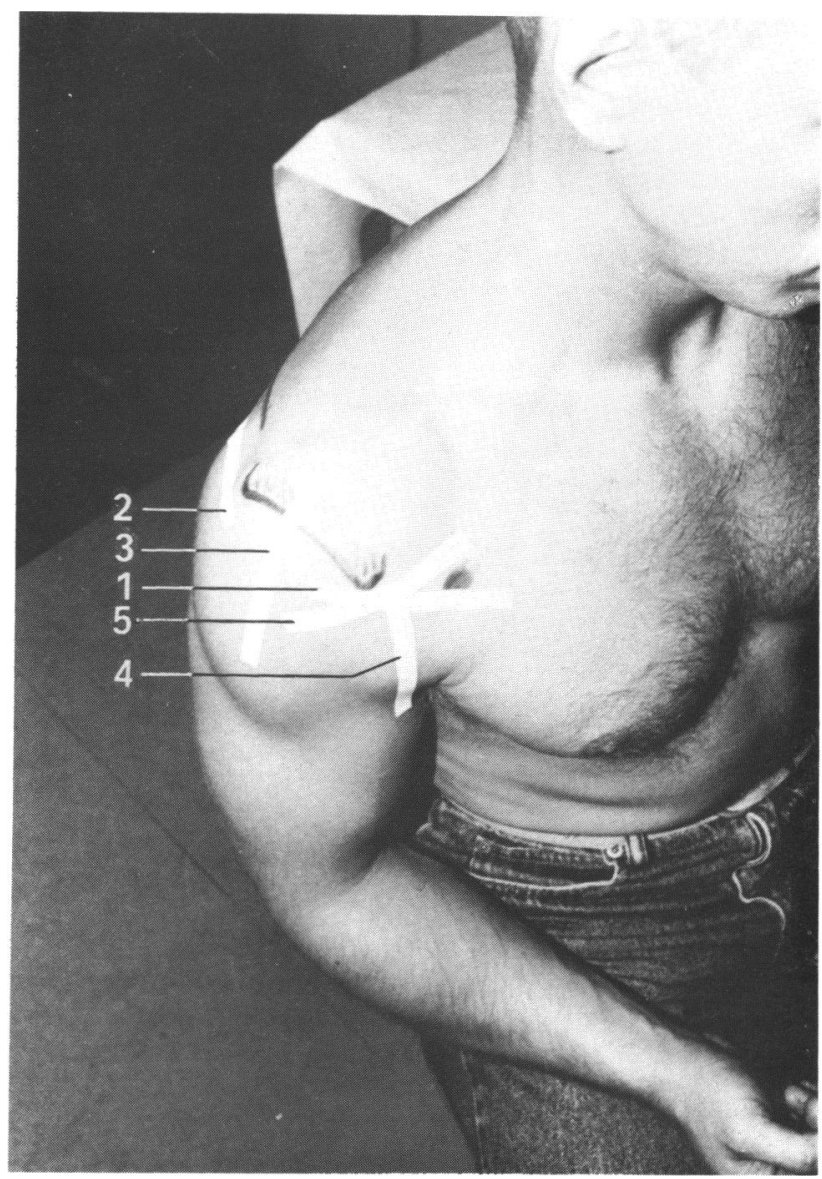

Figure 4. Examination planes on the shoulder (static and dynamic rotation/abduction).

zones indicate older changes such as scarring and degeneration in the sense of fibrotic transformation. Bursae can be found as double contours under the echogenic pattern of deltoid (Figure 6).

In particular, dynamic examination of abduction enables the impingement syndrome to be shown (Figure 7). Typically, the point of pain indication in the so-called painful arc corresponds to the sonographically visualised impingement effect.

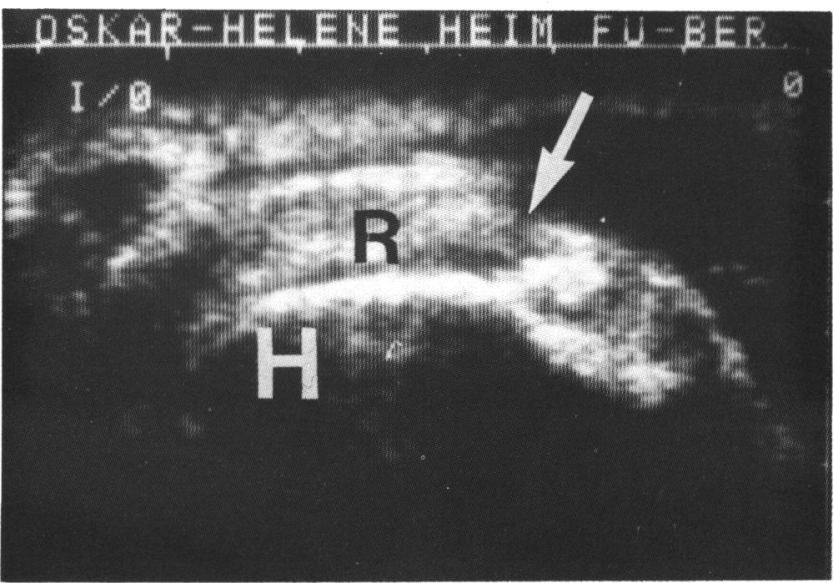

Figure 5. Rotator cuff rupture. Loss of continuity $\rightarrow$ and slight sound densification of rotator cuff $\mathbf{R}$ with small tear in the bursa. $\mathrm{H}=$ head of the humerus with multiple echo under the main reflection zone. 
In the sulcus intertubercularis area, the long biceps tendon is seen as a relatively echo-poor ligament between two echo-rich zones (Figure $8 a$ and $8 b$ ). In the case of degenerative change, relative homogeneity is raised, and synovitis of the tendon becomes visible as double contouring with an echo-poor area over the tendon. Ruptures of the long head of biceps can be seen in the same way. These are grouped with irregular echo-rich zones indicating the degenerative cause of rupture. The examination must be made in several planes so that a rupture is not falsely

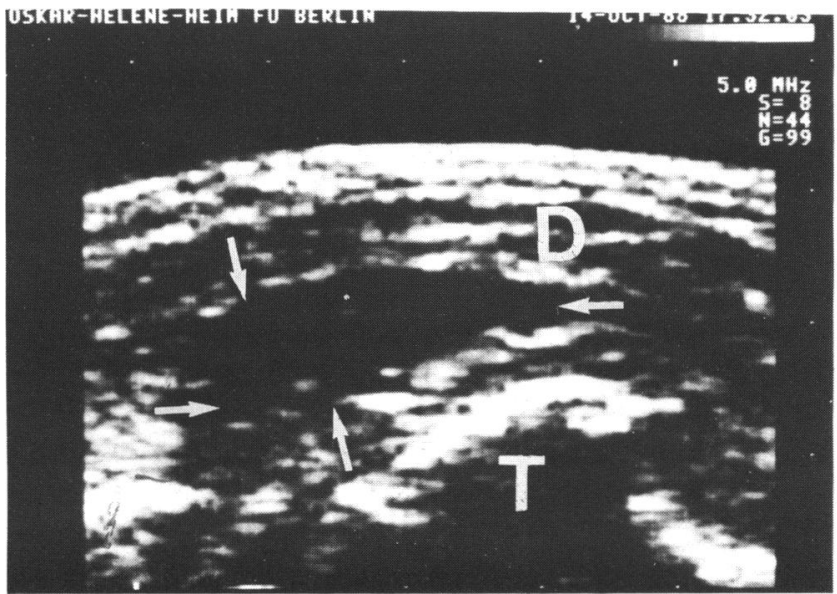

Figure 6. Bursitis subacromialis-subdeltoidea. Clearly marked echo-poor zone $\rightarrow$ between deltoid $D$ and the rotator cuff. Supraspinatus attachment at greater tuberosity $\mathrm{T}$.

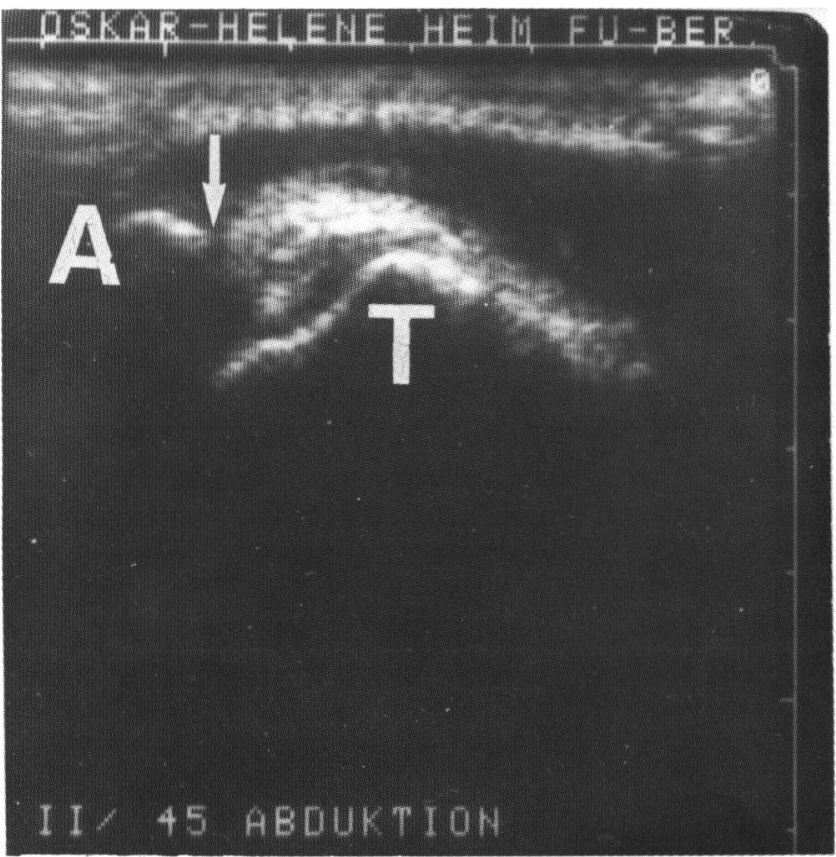

Figure 7. Impingement syndrome. At $45^{\circ}$ abduction, maximum approach of the greater tuberosity $T$ to the acromion $A$ with simultaneous indication of pain from the athlete. $\rightarrow=$ rotator cuff bumping against the acromion $A$. described as positive due to hyper-reflexia of the fossa intertubercularis. Dynamically, luxations of the tendon and co-existing enlargement of the synovial sheath can be well demonstrated (Figure $9 a$ and $9 b$ ).

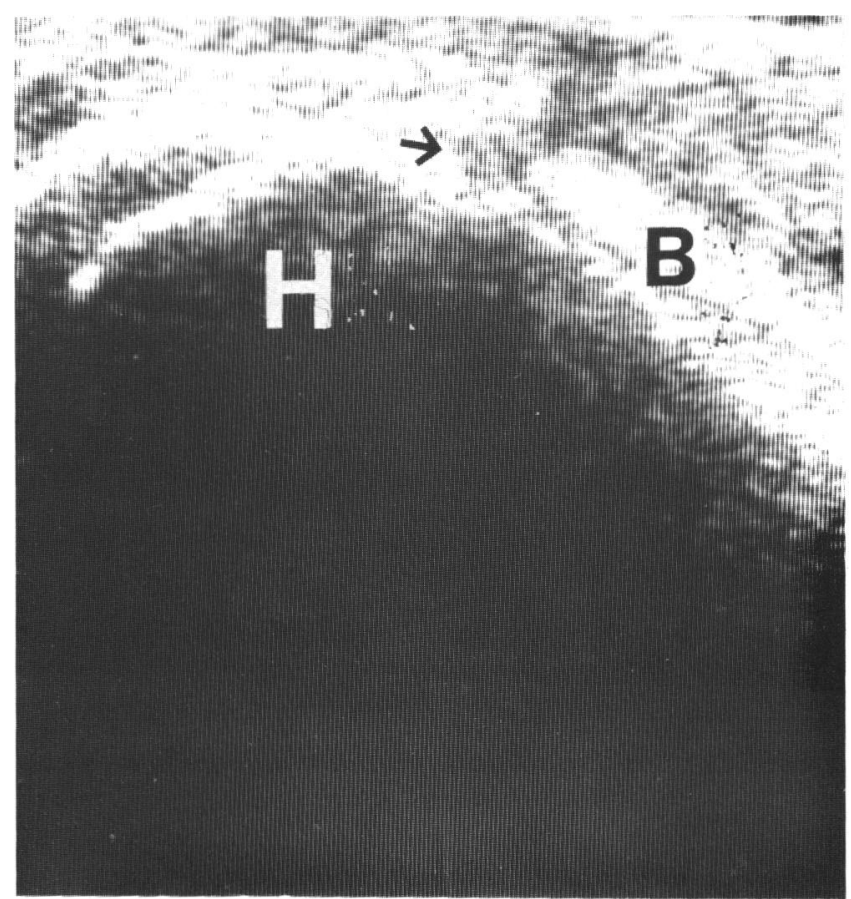

Figure 8a. Rupture of the long biceps tendon B in the fossa intertubercularis. Loss of continuity $\rightarrow$ of the somewhat more sound-proof tendon echoes over the humeral head $\mathrm{H}$. Longitudinal section

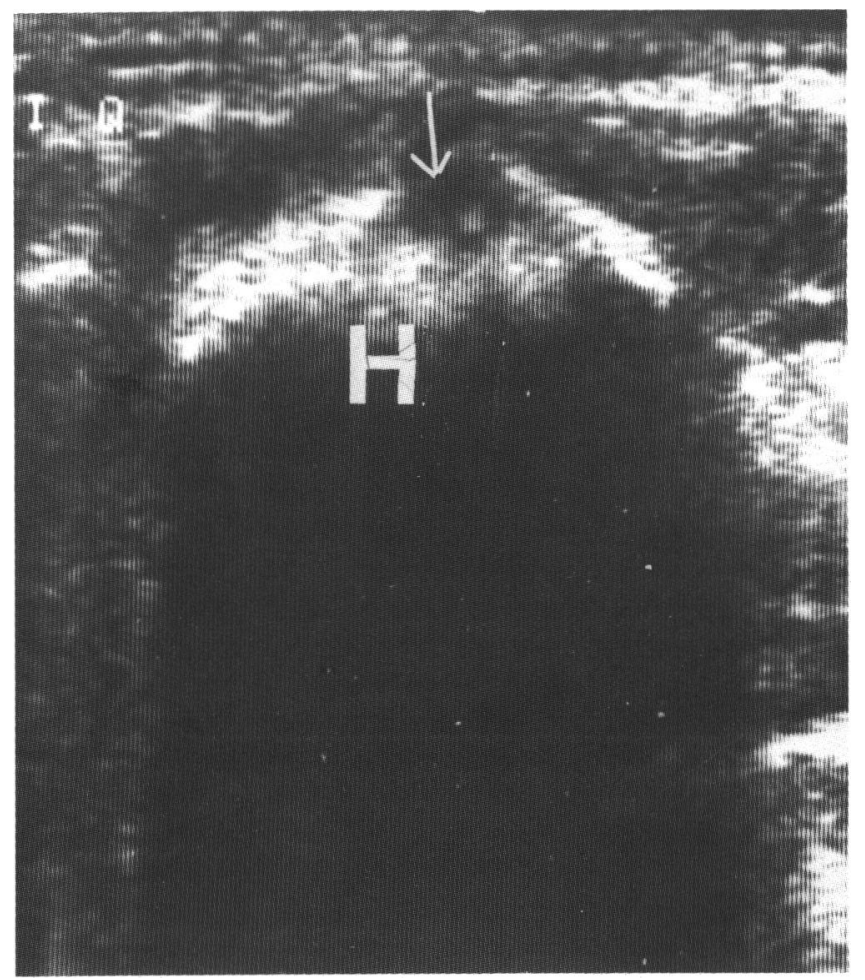

Figure 8b. Transverse section in the fossa intertubercularis $\rightarrow$. Apart from a small hyperdense zone, little evidence of tendon echoes. Transverse ligament rupture. 


\section{Knee}

Sonographic diagnostics in the knee are restricted because of the overshadowing effect of the patella. A classic indication is the evidence of a Baker's cyst in the popliteal fossa ${ }^{10}$ (Figure 10). It is significant for the athlete that here vessel changes in the sense of varicosities can be found as well. A small haemarthrosis can be demonstrated. 'Floating' cartilage can only be identified if not overshadowed by the patella. Lesions of the knee ligaments cannot be shown clearly. Ultrasonic measuring of shifting bone structures enables the identification of instability ${ }^{4,16}$. If direct access with ultrasonic waves is possible, both the surface and the thickness of the articular cartilage can be judged. Effusions of the knee can cause false positive results ${ }^{17}$ (Figure 11a).

The sonographic demonstration of meniscopathy is of interest to various scientific work groups, and accuracies of over 90 per cent have been shown ${ }^{18,19}$. During our investigations, the demonstration of the free ridge have left much to be desired. As these examinations are carried out with a sector scan and a 7.5 $\mathrm{MHz}$ transducer, one may hope for better results

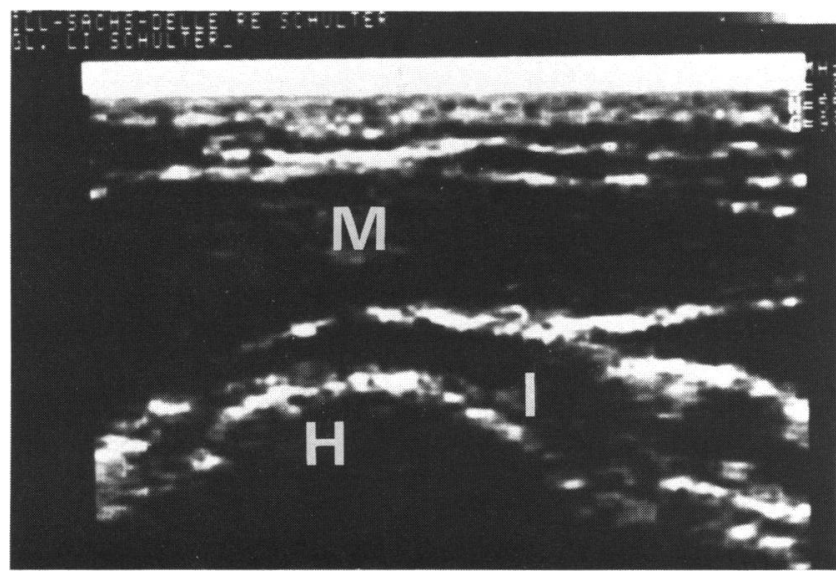

Figure 9a. Position of transducer dorsal, transverse and underneath the spine of the scapula. Normal findings. $M$ $=M$. deltoideus, $I=M$. infraspinatus, $H=$ head of humerous

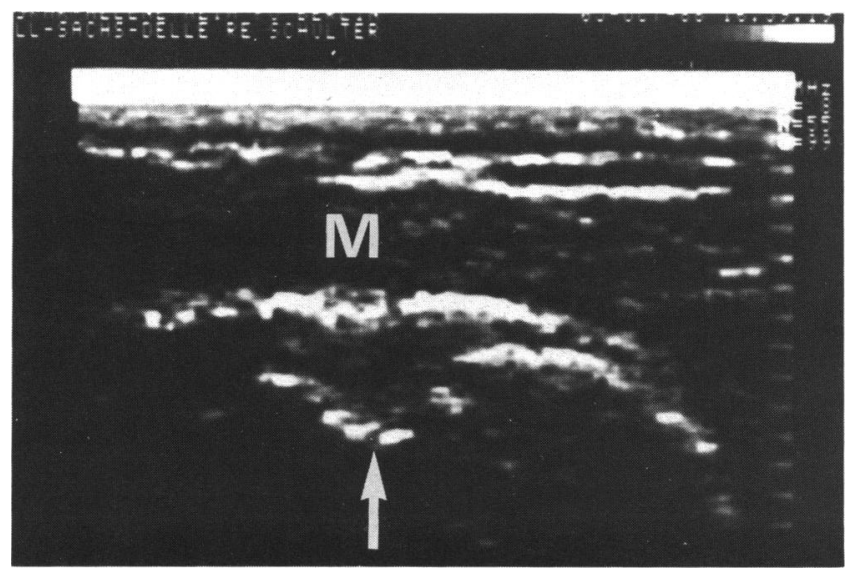

Figure 9b. Position of transducer as in Figure 9a.

Presentation of a Hill-Sachs lesion $\rightarrow$. through technical improvements and improved resolution (Figure 12a).

The demonstration of insertion tendinopathy of the quadriceps tendon and on the apex of the patella and tibial tuberosity is of further significance to the athlete $^{20}$. Hyperechogenic zones in an otherwise homogeneous tendon may be seen in the case of acute complaints. These findings will normalise themselves completely if the process of healing is not disturbed. On the other hand, increased echogeneity may indicate further transformation processes. A clear demarcation of bursae e.g. infrapatellar, can be shown (Figure 12a).

\section{Ankle joint}

Due to surface unevenness, the ankle joint can usually only be examined by using a conduction aid such as a purpose-designed gel or a water-bag. This makes the demonstration of capsule lesions and sometimes ruptured ligaments possible. By means of a manual manipulation, ligament lesions can be identified in sonographic pictures as with pictures imaged similarly during $X$-ray examination ${ }^{16}$. Above all, the demonstration of the peroneal tendon has practical significance. By demonstrating the tendons above the lateral malleolus, a clear differentiation between luxation and ligament lesion can be shown.

\section{Hand}

Due to unevenness, the sonographic examination of the hand and wrist joint area is carried out by using a

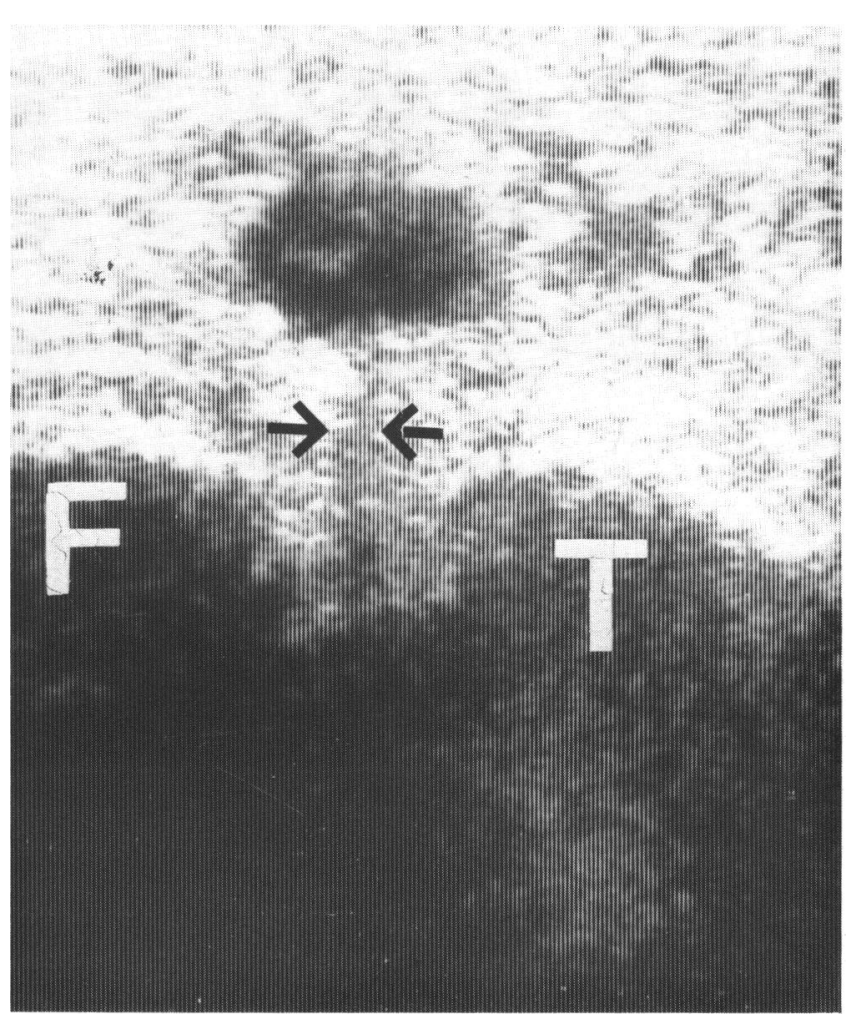

Figure 10. Baker's cyst. Well-defined echo-poor zone with canal $\rightarrow$ reaching to the knee joint cavity. Longitudinal section: $k$ nee dorsal $\mathrm{F}=$ femur, $\mathrm{T}=$ tibia 


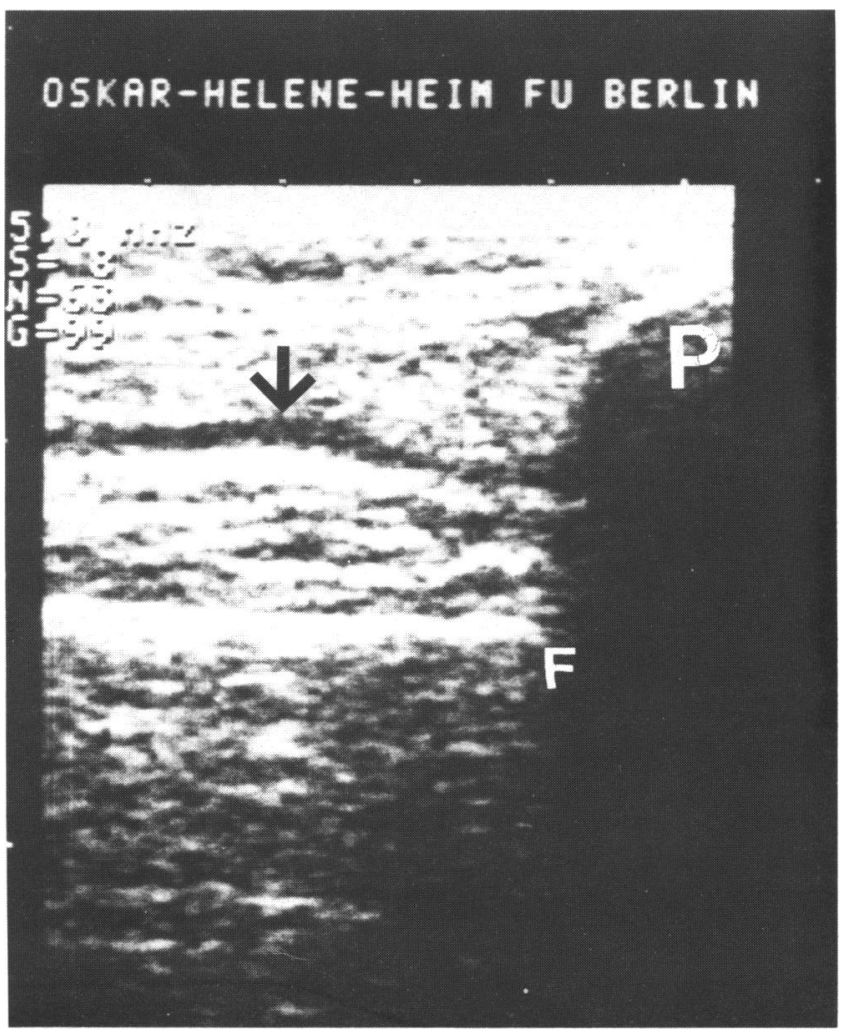

Figure 11a. Slight effusion of knee joint extending to the recessus patellaris $\rightarrow . P=$ patella, $F=$ femur

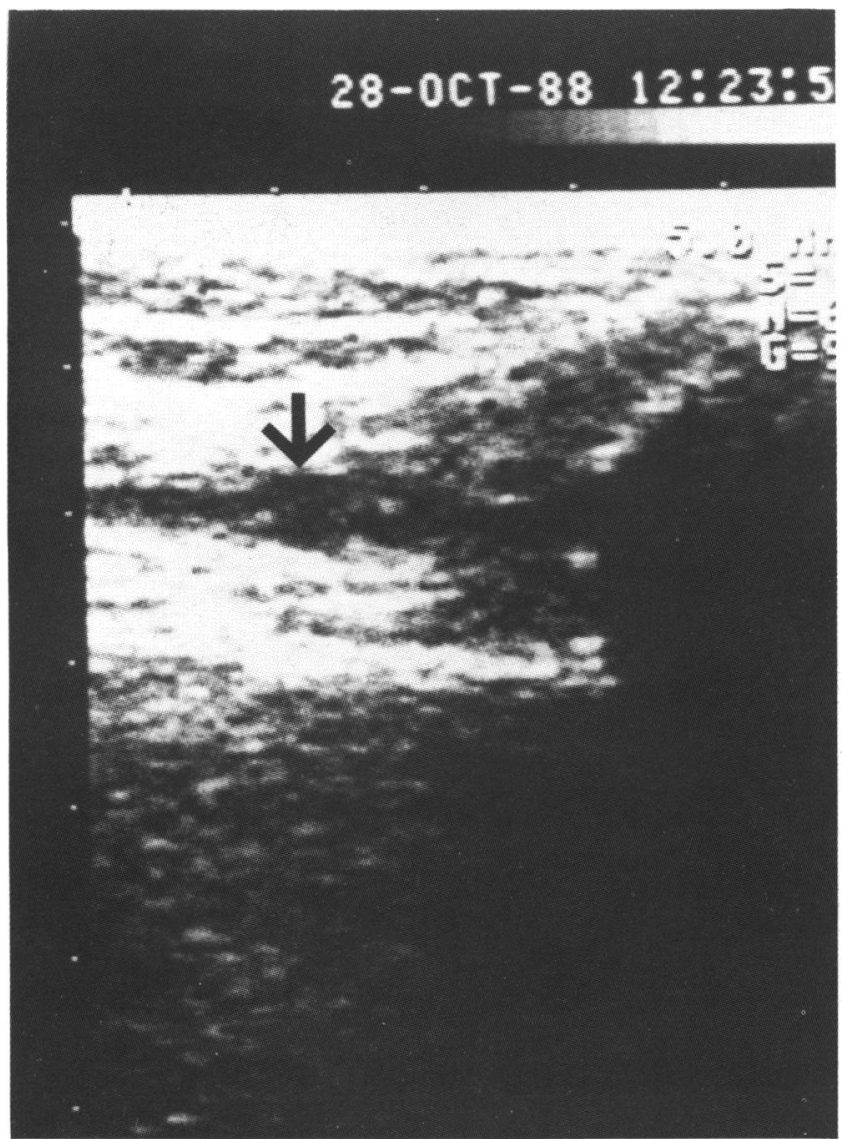

Figure 11b. Pressure from distal on the patella, the recessus suprapatellaris $\rightarrow$ is widened by echo-poor effusion conduction aid. Here the joints and, in particular, ganglia development as well as changes such as tendosynovitis are reproducible. In individual cases, tendon laceration and corresponding retraction can be demonstrated.

\section{Achilles tendon}

Examination of the Achilles tendon takes place in the prone position. Contralateral comparison and $\mathrm{dy}-$ namic examination are necessary here for the exclusion of artefacts. A normal Achilles tendon will be visualised as a medium echogenic ligament, clearly defined by an echogenic band of subcutaneous and subtendinous tissue. Achilles tendon ruptures can be differentiated as long as the ends of the tear are well separated and can be shown by means of dynamic examination ${ }^{3,4,6,10,21}$. When tilting the transducer, however, an echo-poor presentation of the tendon may easily simulate a rupture.

In the frequently diagnostically difficult cases of achillo dynia (Figure 13a and 13b), sonographic differentiations corresponding to the following criteria can be undertaken ${ }^{21}$ :

Differences in thickness of the Achilles tendon itself are in contrast to the merely broadened peritendinous echo in the peritendonitis. Localised widening of the tendon together with intratendinous echo-poor zones point to oedematisation, or with echogenic zones to necrosis.

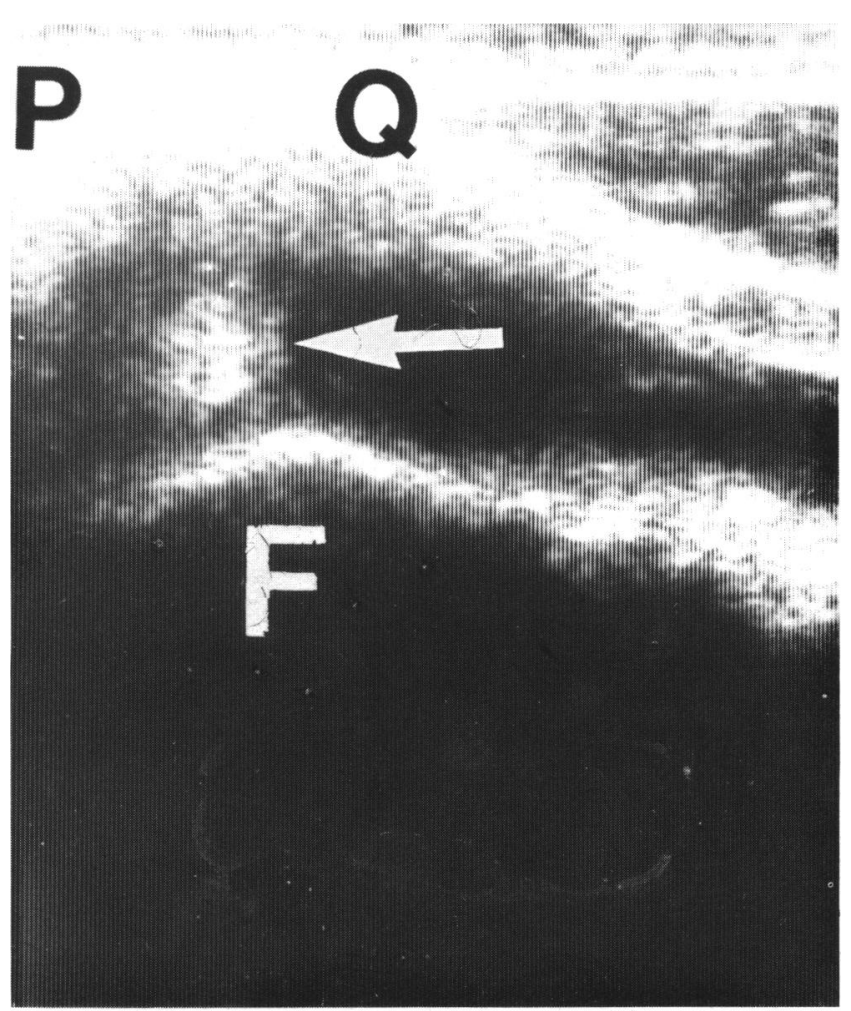

Figure 11c. Free-floating cartilage $\rightarrow$ in the upper recess of the knee. Underneath the echogenic quadriceps tendon $Q$, echo-poor zone represents effusion in the suprapatellar pouch with echogenic representation of free-floating cartilage. Longitudinal section $P=$ patella, $F$ $=$ femur 
Intratendinous echos: Localised mainly rounded echo-rich zones, partly with distal acoustic shadowing, point to necrosis with partial calcification. Longish echo-rich tendons can be seen as valid expressions of degenerative change.

Suppressions: These can result from tumours which present themselves in various degrees of echogenicity, and also occasionally through rounded echo-poor equivalents of the Achilles bursa under the attachment to the calcaneus (Figure 14).

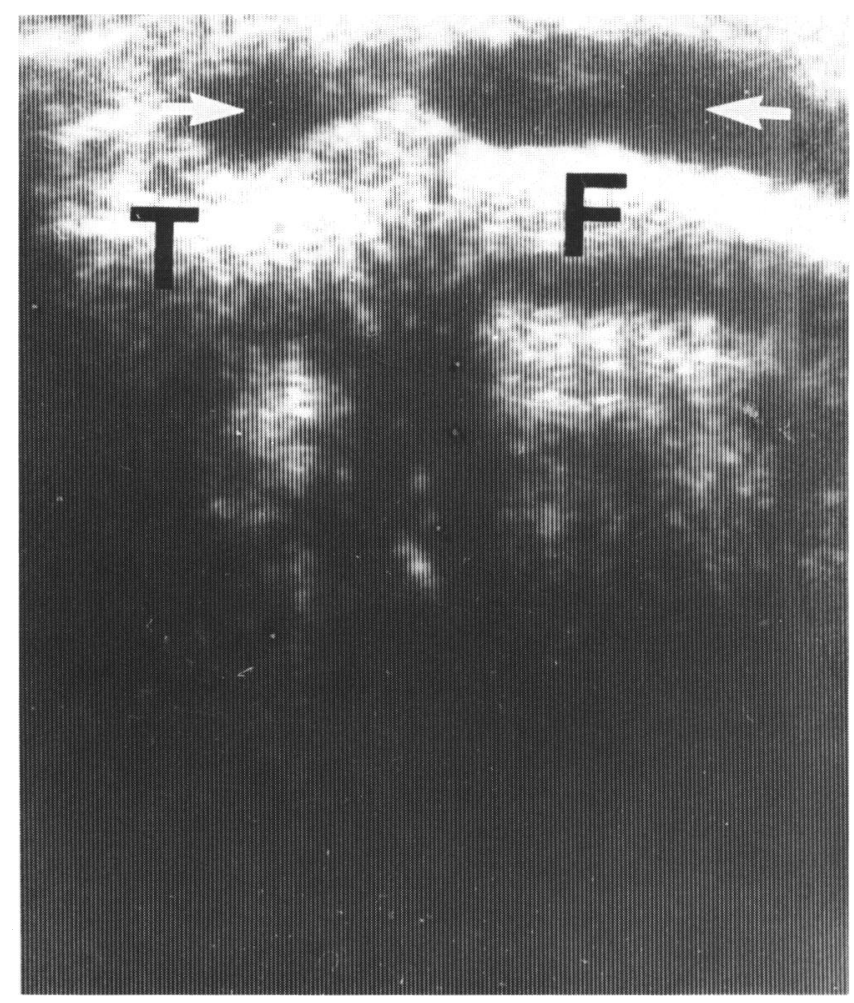

Figure 12a. Meniscal cyst. Clearly defined echo-poor zone $\rightarrow$ over the medial joint cavity. Longitudinal section $\mathrm{F}=$ femur, $\mathrm{T}=$ tibia

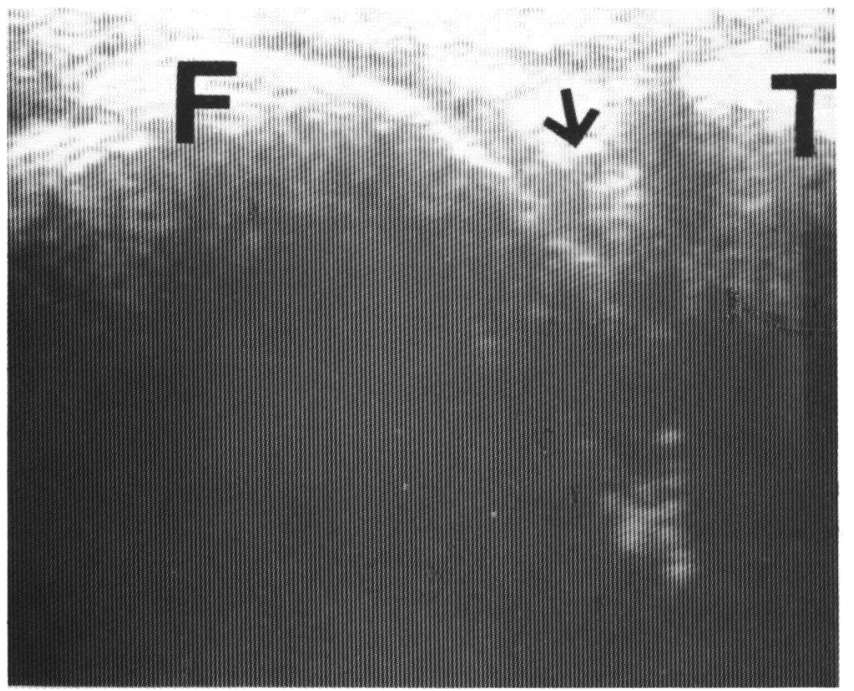

Figure 12b. Meniscus tear (basket handle). Loss of meniscal continuity $\rightarrow$ with sound densification in the rupture zone. Longitudinal section $\mathrm{F}=$ femur, $\mathrm{T}=$ tibia

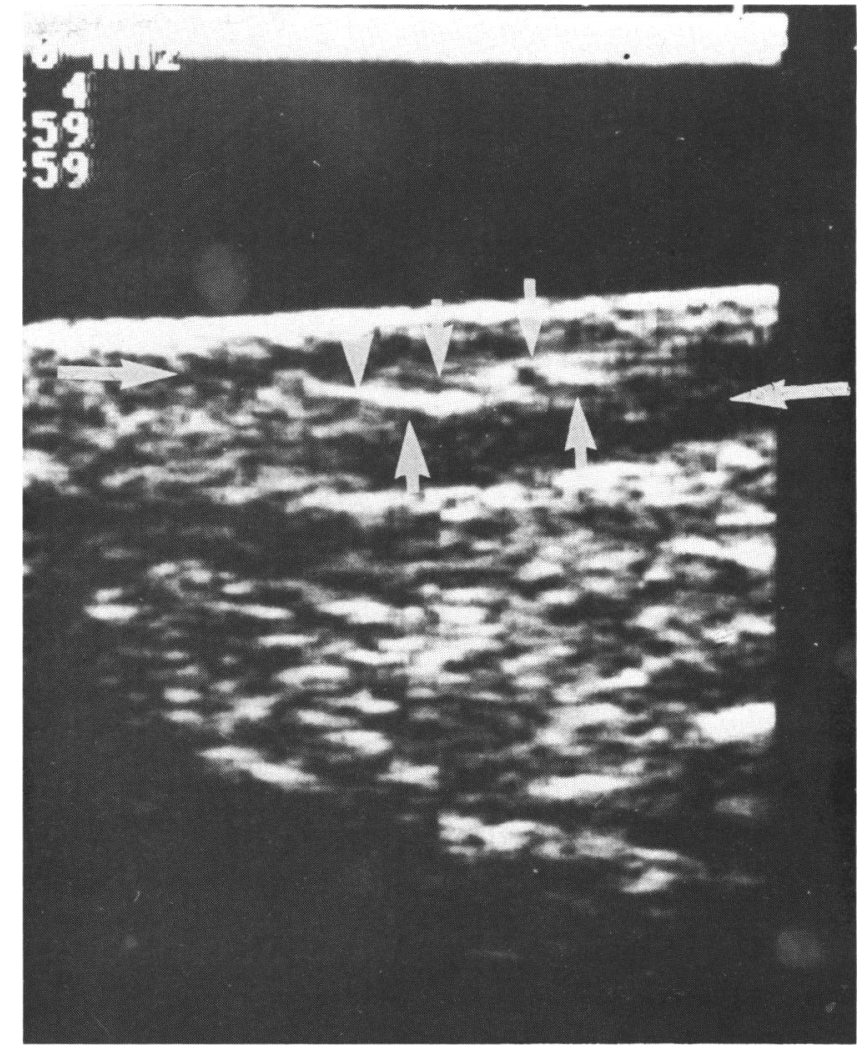

Figure 13a. Achillodynia: broadening and echo-poor representation of the Achilles tendon $\downarrow$, an accompanying paratenonitis shown as echo-poor $\rightarrow$

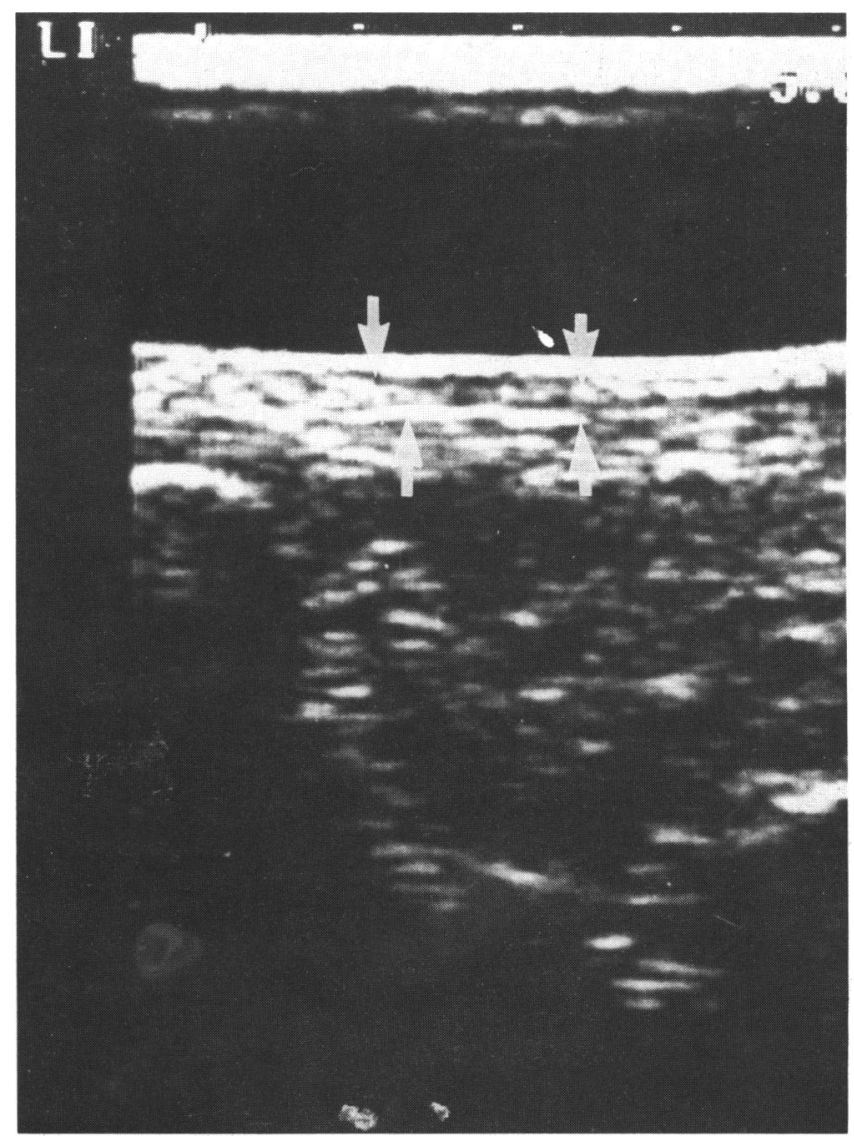

Figure 13b. Control sonography. Intact contralateral Achilles tendon $\rightarrow$ 
To summarise, in the Achilles tendon, differentiation of degenerative change from peritendinous causes of achillodynia can be effected as can visualisation of complete and partial ruptures.

\section{Bones}

Sound is completely reflected from bony surfaces. Irregularities on the surface, as well as zones of sound permeability e.g. after fractures, luxations or changes to the apophysis, are suitable for examination. The process of healing can be followed. The degree of fracture healing can be determined by the restriction of sound entry. Thereby, at least, it is possible to economise partly on X-ray examinations.

\section{Discussion}

In many authors' estimation, sonography can be excellently employed as a screening method for the clarification of lesions of the soft tissue in the locomotor system ${ }^{3-7,10,13}$. Sensitivity and specifity of the examination methods have been correlated with cadaver studies, at operation, or through other diagnostic methods (computed tomography, nuclear magnetic resonance, arthroscopy, arthrography) ${ }^{2-7,11}, 13-15,17-21$.

Pfister outlined the sources of technical error and warned against over interpretation and false negative results ${ }^{7}$. Examiners' mistakes appear due to wrong positioning of the patient as well as incorrect focusing of the apparatus (amplification, depth equalisation). In principle, visualisation of lesions must be possible in several planes and non-reproducible findings should not be evaluated. Multiple echos released by secondary reflections near the tansducer are caused by mistakes made in the examination process

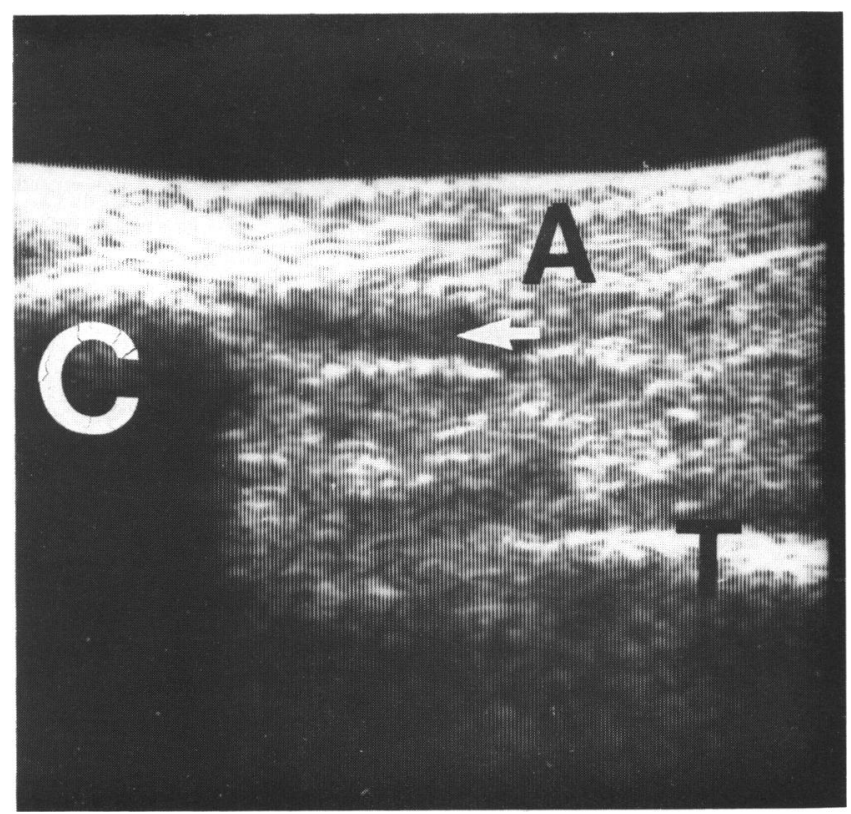

Figure 14. Calcaneal búrsitis: underneath the inconspicuous Achilles tendon A, echo-poor zone $\rightarrow$ with sound amplification. Longitudinal section $\mathrm{C}=$ calcaneus, $\mathrm{T}=$ tibia (artefacts). On the other hand, sound amplification on the reverse side of the fluid-filled spaces is used as proof of content e.g. bursa. It is not possible to make an evaluation of structures lying behind very echogenic tissue, e.g. bones.

Apparatus related mistakes occur through inadequate resolution of small lesions $(2-4 \mathrm{~mm})$ and small structures outside the line of focus can cause false negative findings.

Great demands are made of the examiner concerning the anatomical ordering of his evidence. The danger of false positive findings is lessened by making a comparison with the normal contralateral side, and for this reason should always be carried out. Although there is a relatively high sensitivity in the process, findings should be further clarified e.g. arthrosonography, arthroscopy, angiography, CT, $\mathrm{PE}$, because of the relatively negligible specifity here.

Finally, it should be mentioned, that in sports medicine today the critical application of sonography should be routinely used as a further screening method. Possibly in the future, technical improvements e.g. transmission sonography ${ }^{3}$ will be able to show injuries to the soft tissue more clearly and quickly, and in time replace other methods such as radiology completely.

\section{References}

1 Hollmann, W. Risikofaktoren in der Entwicklung des Hochleistungssportes. In: H. Rieckert (Hrsg.): Sportmedizin - Kursbestimmung. Dtsch. Sportärztekongreß 1986. Springer-Verlag, Berlin - Heidelberg 1987

2 Henche, H.R. and Hey, W. (Hrsg) Sonographie in der Orthopädie und Sportmedizin Med Lit Verlagsges Uelzen, 1987

3 Stuhler, T. and Feige, A. (Hrsg) Ultraschalldiagnostik des Bewegungsapparates. Springer-Verlag, Berlin Heidelberg, 1987

4 Graf, R. Was leistet die Donographie in der Sporttraumatologie Dtsch Z Sportmed 1987, 38, 82-85

5 Fornage, B.D. Accidents musculaires du sportif Nouv Presse Med 1982, 8, 11

6 Fornage, B.D. Sonography of Muscles, Tendons and Other Soft Tissues of the Extremities. Technique and Normal Results. In: Otter and P. Schwars (Hrsg) Ultraschalldiagnostik, Georg Thieme Verlag, Stuttgart, 1986

7 Pfister, A. Experimentelle und klinische Ergbnisse der Ultraschallsonographie bei sportorthopädischen Weichteilerkrankungen Sportverb Sportsch 1987, 3, 130-141

8 Groher, W. Verletzungen und Schäden der Skelettmuskulatur: Nomenklatur, Häufigkeit, Charakteristika. In: Franz, I.W., Mellerowicz, H. and Noack, W. (Hrsg): Training und Sport zur Prävention und Rehabilitation in der technischen Umwelt. SpringerVerlag, Berlin, 1985, 130-135

9 Franke, K. Traumatologie des Sports. VEB Verlag Volk und Gesundheit, Berlin, 1986

10 Braun, B., Günther, R. and Schwerk, W.B. (Hrsg) Ultraschalldiagnostik - Lehrbuch und Atlas. Ecomed Verlag, Landsberg/Lech 1986. 4. erg. Aufl

11 Fornage, B.D., Touche, D.M. Segal, P. and Rifkin M.D. Ultrasonography in the evaluation of muscular trauma J Ulrasound Med 1983, 2, 549-554 
12 Kramer, F.L., Kartz, A.B., Rubin C. and Goldberg B.B. Ultrasound Experience of Myositis ossificans Skeletal Radiol 1979, 4, 19

13 Hedtmann, A., Fett, H. and Moraldo, M. Ultraschalldiagnostik der Schulter bei Sportverletzungen Dtsch Z Sportmed 1987, 38, 86-99

14 Hedtmann, A., Weber, A., Schleberger, R. and Fett, H. Ultraschalluntersuchung 'des Schultergelenkes Orthop Prax 1986, 9, 647-661

15 Jungbluth, K. H., Holst, A., Triebel, H. J. and Wening, J.V. Die Sonographie als Screeningmethode bei Verdacht auf Ruptur der Rotatorenmanschette Unfallchirurgie 1987, 13, 60

16 Schricker, T., Hien, N.M. and Wirth, C.J. Klinische Ergebnisse sonographischer Funktionsuntersuchungen bei Kapselbandläsionen an Knie- und Sprunggelenk Ultraschall 1987, 8, 27-31
17 Helzel, M.V., Schindler, G. and Gay, B. Sonographische Messung des Gelenkknorpels züber dem Femurkondylus Fortschr Geb Röntgenstrahlen Nukl med 1987, 147, 10-14

18 Gerngroß, H., Sohn, Ch. and Griesbeck, F. Wertigkeit, Technik und klinische Anwendung der Meniskussonographie Unfallchirurg 1987, 90, 173

19 Sohn, Ch., Gerngroß, H., Bähren, W. and Sobodnik, W. Sonographie des Meniskus und seiner Läsionen Ultraschall 1987, 8, 32-36

20 Fornage, B.D., Rifkin, M.D., Touche, D.M. and Segal, P.M. Sonography of the Patellar Tendon - Preliminary Observations Am J Röntgenol 1984, 143, 179-182

21 Gondolph-Zink, B., Scheiderer, W. and Eisenlauer, G. Sonographie von Schillessehnenverletzungen bei Sportlern Sportverb Sportsch 1987, 2, 96-99 